\title{
The Relationship between Hair Zinc Levels and Drug-resistant Epilepsy in Children at Sanglah Hospital
}

\author{
I Gusti Ngurah Made Suwarba*, Dewi Sutriani MahaliniD, I Gusti Ngurah Agung Jayadhi Widyakusuma \\ Department of Child Health, Faculty of Medicine, Udayana University, Sanglah Hospital, Denpasar, Bali, Indonesia
}

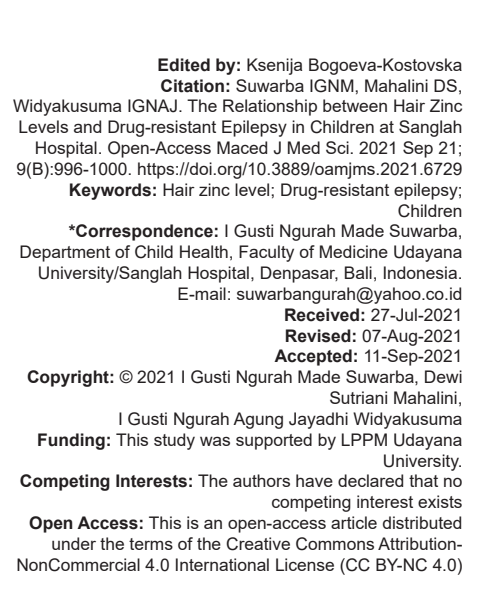

\begin{abstract}
BACKGROUND: Drug-resistant epilepsy (DRE) is epilepsy that is failed to achieve free of seizure after adequate trials of two tolerated and appropriately chosen antiepileptic drugs. Zinc deficiency could trigger the onset of various neurological disorders, including seizures in epilepsy.

AIM: The objective of the study was to determine the relationship between hair zinc levels and DRE in children at Sanglah Hospital, Denpasar.

METHODS: This is an analytic observational study using a cross-sectional design, involving 74 subjects. The inclusion criteria were children aged 1 month-18 years who had been diagnosed with epilepsy. Chi-square test and multivariate analysis with logistic regression were used to assess the relation between hair zinc levels and DRE in children.

RESULTS: Multivariate analysis found a relationship between low hair zinc level and DRE in children (PR 8.0; 95\% $\mathrm{Cl} 2.0-32.2 ; p=0.003$ ). The duration of therapy (PR 16.0; 95\% CI 3.9-65.4; $p=0.000$ ) and structural abnormalities (PR 4.1; 95\% Cl 1.1-14.9; $p=0.028$ ) also increased the risk of DRE in this study.

CONCLUSION: Low hair zinc level is associated with DRE in children.
\end{abstract}

\section{Background}

Epilepsy is one of the main problems in pediatric neurology and requires long-term treatment. The remission rate in epilepsy treatment with antiepileptic drugs (AED) is about $60-70 \%$. Approximately $30-40 \%$ of patients have drug-resistant epilepsy (DRE) [1]. International League Against Epilepsy in 2009 defines DRE as failure of adequate trials of two tolerated and appropriately chosen AED schedules (whether as monotherapies or in combination) to achieve seizure freedom [2].

About 50 million people are currently estimated to have active epilepsy, with approximately $40 \%$ of cases in children and adolescents [3]. The prevalence of epilepsy in developed countries is $4-9 / 1000$ population, with an incidence of $25-50 / 100,000$ population per year, while in developing countries, the prevalence and the incidence are 14-57/1000 population and $30-115 / 100,000$ population per year, respectively [2]. The previous study at three major hospitals in Jakarta, including children under the age of 5 years, reported that the incidence of DRE in Jakarta was $18.2 \%$, while at Sanglah Hospital, Denpasar, the incidence of DRE in children aged $1-12$ years was $21.7 \%$ [4], [5].
Several risk factors of epilepsy and DRE have been identified, including clinical risk factors, neurophysiology, neurotransmitters, and neuroimaging [6]. Clinical risk factors for DRE, including epilepsy syndrome, initial response to AED, frequency of seizures at the beginning of diagnosis, age, interictal electroencephalogram changes, and the presence of concomitant diseases [1]. The mechanism of neurotransmitter factors in causing epileptic conditions and DRE has not been not fully understood. The previous study reported that ion transporter at voltage gate is hypothesized to be responsible for the development of epilepsy symptoms [7]. Several minerals and elements have an essential role in nervous system development. Zinc deficiency could trigger the onset of various neurological disorders, including the incidence of seizures in epilepsy [8]. Zinc is generally found in the brain (hippocampus) as an important element for communication between neurons and the function of inhibitory neurotransmitter, gamma-aminobutyric acid (GABA). Zinc regulates the formation of glutamic acid decarboxylase enzyme, which has an important role in GABA synthesis [7].

Prasad et al. found that low levels of zinc were associated with the incidence of genetic generalized epilepsy [7]. Several previous studies have found 
significant differences in lower serum zinc levels in people with epilepsy [8], [9]. However, serum zinc concentration tends to vary depending on daily intake. Zinc levels in tissue, such as nails and hair, tend to have more stable concentration due to slower rate of metabolism. Hair samples are easier to obtain, thus, it is better to use for sampling. In this study, we conducted a research to analyze the relationship between hair zinc levels with the incidence of DRE in children with epilepsy at Sanglah Hospital, Denpasar.

\section{Methods}

This study was an analytic observational study using cross-sectional design. It was conducted in pediatric outpatient clinic and inpatient room of Sanglah Hospital, Denpasar, Bali, Indonesia, from May until August 2020. The subject in this study was all patients aged 1 month until 18 years old who suffered from epilepsy and taken AEDs. We excluded all children with (1) damaged hair follicles (patients who received chemotherapy, radiation, and/or infection of the hair follicles); (2) children who did not have hair; (3) the presence of intracranial malignancy or infection; (4) moderate and severe malnutrition; (5) history of taking multivitamin and/or zinc supplements; and (6) those who received antiepileptic treatment other than the AEDs carbamazepine, phenobarbital, phenytoin, and valproic acid.

The data included age, gender, history of brain structural disorder (infection, trauma, or brain malformation), hair zinc level, and the status of DRE. DRE in this study is defined as epilepsy with good adherence to two or more AEDs and seizures still occur more than once a month. The hair sample was collected from the occipital, temporal, and parietal region; the hair was cut approximately $2 \mathrm{~cm}$ near the scalp, then stored in a tube at room temperature. The hair samples were collected by research staff every 2 weeks and analyzed by laboratory staff to get hair zinc level using spectrometer machine type (inductively coupled plasma emission [ICPE])-9000 in Laboratory of Udayana University.

Collected data were analyzed using SPSS program for Windows version 23.0. In descriptive analysis, categorical scale data are expressed in frequency distribution and percentage, displayed in narrative and table form. Chi-square test and multivariate analysis with logistic regression tests were used to determine the relationship between zinc hair levels and DRE with a significance limit $p<0.05$ and $95 \%$ confidence interval. This study was approved by the Research Ethics Committee of the Faculty of Medicine, Udayana University and Sanglah General Hospital, Denpasar (1012/UN14.2.2.VII.14/LT/2020).

\section{Results}

A total of 91 patients with epilepsy were found during this research period, of which 17 patients were excluded from the study. The group consisted of 37 patients in the DRE group and 37 patients in the drug-sensitive group with a total of 74 patients who met the inclusion criteria. All subjects underwent a research procedure and hair zinc levels were examined at Analytic Laboratory Udayana University. The characteristics of sample in this study are presented in Table 1. There is no significant difference in the proportion of gender, age, nutritional status, and history of epilepsy in family, between the two groups. The majority of the subjects in the two groups were aged over 5 years and had malnutrition. In DRE group, structural abnormalities were found more frequently in the drug-resistance group compared to drug-sensitive group $(59.1 \%$ vs. $35.1 \%)$. Carbamazepine was the most commonly used medication both in the drugresistant group and drug-sensitive group, with the percentage of $97.3 \%$ and $64.9 \%$, respectively, followed by valproic acid, with the percentage of $83.8 \%$ and $59.5 \%$, respectively.

Table 1: Characteristics of research subjects

\begin{tabular}{|c|c|c|}
\hline Variable & $\begin{array}{l}\text { DRE } \\
n=37\end{array}$ & $\begin{array}{l}\text { Drug-sensitive epilepsy } \\
n=37\end{array}$ \\
\hline \multicolumn{3}{|l|}{ Gender } \\
\hline Male & $22(59.5)$ & $20(54.0)$ \\
\hline Female & $15(40.5)$ & $17(46.0)$ \\
\hline \multicolumn{3}{|l|}{ Age } \\
\hline$\leq 5$ years old & $8(21.6)$ & $17(45.9)$ \\
\hline$>5$ years old & $29(78.4)$ & $20(54.1)$ \\
\hline \multicolumn{3}{|l|}{ Mild malnutrition } \\
\hline Yes & $24(64.9)$ & $22(59.5)$ \\
\hline No & $13(35.1)$ & $15(40.5)$ \\
\hline \multicolumn{3}{|c|}{ History of epilepsy in family } \\
\hline Yes & $29(78.4)$ & $35(94.6)$ \\
\hline No & $8(21.6)$ & $2(5.4)$ \\
\hline \multicolumn{3}{|c|}{ Duration of therapy } \\
\hline$\geq 2$ years & $27(73.0)$ & $11(29.7)$ \\
\hline$<2$ years & $10(27.0)$ & $26(70.3)$ \\
\hline \multicolumn{3}{|c|}{ Structural abnormalities } \\
\hline Yes & $22(59.5)$ & $13(35.1)$ \\
\hline No & $15(40.5)$ & $24(64.9)$ \\
\hline \multicolumn{3}{|c|}{ History of therapy } \\
\hline Monotherapy & $0(0)$ & $21(56.8)$ \\
\hline Polytherapy & $37(100)$ & $16(43.2)$ \\
\hline
\end{tabular}

\section{Relationship between hair zinc levels and}

\section{DRE}

In this study, we performed bivariate analysis between hair zinc levels and external variables against the incidence of DRE, as described in Table 2. Based on bivariate analysis, most of the children with DRE significantly had lower hair zinc levels (73\%) compared to drug-sensitive epilepsy group (48.6\%) with prevalence ratio $1.74(95 \% \mathrm{Cl} 1.08-7.55 ; p=0.032)$. History of epilepsy in the family also increased the risk of DRE with prevalence ratio 1.76 compared to the drug-sensitive epilepsy group $(95 \% \mathrm{Cl} 1.17-2.66$; $p=0.041$ ). Treatment duration of more than 2 years and structural abnormalities were found to be the factors that increased the risk of DRE with prevalence ratio of 
$2.55(95 \% \mathrm{Cl} 1.45-4.49 ; \mathrm{p}=0.000)$ and $1.63(95 \% \mathrm{Cl}$ $1.02-2.61 ; p=0.036)$, respectively.

Table 2: Bivariate analysis of the relationship between hair zinc levels and external variables with DRE

\begin{tabular}{|c|c|c|c|c|c|}
\hline \multirow[t]{2}{*}{ Variable } & \multicolumn{2}{|l|}{ Epilepsy } & \multirow[t]{2}{*}{ PR } & \multirow[t]{2}{*}{$95 \% \mathrm{Cl}$} & \multirow[t]{2}{*}{$\mathrm{p}$-value } \\
\hline & $\begin{array}{l}\text { Drug resistant } \\
(\mathrm{n} / \%)\end{array}$ & $\begin{array}{l}\text { Drug } \\
\text { sensitive } \\
(\mathrm{n} / \%)\end{array}$ & & & \\
\hline \multicolumn{6}{|l|}{ Gender } \\
\hline Male & $22(59.5)$ & $20(54.0)$ & 1.24 & $0.49-3.13$ & 0.639 \\
\hline Female & $15(40.5)$ & $17(46.0)$ & & & \\
\hline \multicolumn{6}{|l|}{ Age } \\
\hline$\leq 5$ years & $8(21.6)$ & $17(45.9)$ & 1.55 & $0.61-3.92$ & 0.348 \\
\hline$>5$ years & $29(78.4)$ & $20(54.1)$ & & & \\
\hline \multicolumn{6}{|l|}{ Zinc levels } \\
\hline Low & $27(73.0)$ & $18(48.6)$ & 1.74 & $1.08-7.55$ & 0.032 \\
\hline Normal & $10(27.0)$ & $19(51.4)$ & & & \\
\hline \multicolumn{6}{|c|}{ History of epilepsy in the family } \\
\hline Yes & $29(78.4)$ & 35 (98.6) & 1.76 & $1.17-2.66$ & 0.041 \\
\hline No & $8(21.6)$ & $1(5.4)$ & & & \\
\hline \multicolumn{6}{|c|}{ Duration of therapy } \\
\hline$\geq 2$ years & $27(73.0)$ & $11(29.7)$ & 2.55 & $1.45-4.49$ & 0.000 \\
\hline$<2$ years & $10(27.0)$ & $26(70.3)$ & & & \\
\hline \multicolumn{6}{|c|}{ Structural abnormalities } \\
\hline Yes & $22(59.5)$ & $13(35.1)$ & 1.63 & $1.02-2.61$ & 0.036 \\
\hline No & $15(40.5)$ & $24(64.9)$ & & & \\
\hline
\end{tabular}

Multivariate analysis also found that low hair zinc levels, duration of therapy, and structural abnormalities were significant risk factors for the occurrence of DRE (Table 3). The risk of DRE was 8 times higher in children with low hair zinc levels (PR 8.0; 95\% Cl 2.0-32.2; $p=0.003)$. Similarly, the duration of therapy and structural abnormalities increased the risk of DRE with prevalence ratio of $16.0(95 \% \mathrm{Cl} 3.9$ $65.4 ; p=0.000)$ and $4.1(95 \% \mathrm{Cl} 1.1-14.9 ; p=0.028)$.

Table 3: Multivariate analysis of risk factors associated with DRE

\begin{tabular}{llll}
\hline Variable & $\mathrm{PR}$ & $95 \% \mathrm{Cl}$ & $\mathrm{p}$-value \\
\hline Low level of zinc & 8.0 & $2.0-32.2$ & 0.003 \\
History of epilepsy in the family & 4.6 & $0.6-32.1$ & 0.120 \\
Duration of therapy $\geq 2$ years & 16.0 & $3.9-65.4$ & 0.000 \\
Structural abnormalities & 4.1 & $1.1-14.9$ & 0.028 \\
\hline DRE. Drug-resistant epilepsy & &
\end{tabular}

\section{Discussion}

In our study, we did not find any significant difference in sex and nutritional status of subjects in the drug-resistant and drug-sensitive epilepsy group. The majority of subjects in both groups were male, 59.6\% in drug-resistant and $54 \%$ in drug-sensitive epilepsy group. This result could be explained by differentiation of cationchloride cotransporters (CCCs) expression between males and females. CCCs regulate the neuronal chloride gradient and strongly affect the electrical response to the inhibitory neurotransmitter, GABA. Sexually dysmorphic modulation of chloride regulation may be one of the underlining key mechanisms of the differences in seizure susceptibility and refractory incidence between males and females [10].

The majority of patient in this study is older than 5 years old. According to Minardi et al., the peak incidence of epilepsy occurs in children aged younger than 15 years old with $50.14 / 100.000$ new cases per year [11]. On the contrary, another study showed that the highest incidence of epilepsy was found in the $1^{\text {st }}$ years of life. The mechanism of drug resistance is influenced by many variables. Age is one of the variables that can affect the outcome of patients with seizure-free rate that is higher in adults. Most of the studies related to ours were done in adult population, however, it is suggested that the same result would be obtained in children population [1].

In this study, the proportion of malnutrition was higher in both drug-resistant and drug-sensitive groups, with $64.9 \%$ and $59.6 \%$, respectively. Nutritional status is associated with the incidence of epilepsy. Malnutrition can influence amino acid level of neurotransmitter inhibitors and explained the decreasing levels of GABA in the cortex of epilepsy patients. Low consumption of amino acid or its precursor may reduce the availability of inhibitory neurotransmitters in the brain. This finding is supported by research conducted in animal studies. The animal experiment using low-protein diet showed the depletion of GABAergic neurons density in hippocampus [12].

Most of the subjects in this study had a family history of epilepsy. The same result was also explained in a study conducted in Turkey about the risk factors of epilepsy in children. The study showed that family history has an effect on epilepsy in which the risk of epilepsy is approximately 4.75 times higher in children with family history of epilepsy compared to children without family history of epilepsy. The incidence of epilepsy is also increased in children with the history of consanguinity. The proportion of low hair zinc levels in the drug-resistant group is about $73 \%$, higher than the drug-sensitive group. Multivariate analysis results showed that low hair zinc levels can increase the risk of DRE by 8 times. These results are consistent with the previous study by Seven et al. which showed that serum zinc levels were significantly lower in idiopathic intractable epilepsy compared to healthy children [13].

There are several theories about the etiology of DRE. Under normal conditions, multidrug transporter will prevent the entry of various lipophilic or xenobiotic toxins from the blood to the brain by certain mechanism. This transporter also works actively when it is necessary to transport the epileptic drugs to the brain by preventing AEDs from reaching the brain at the certain level. Drug transporter is regulated in a different complex process which is influenced by oxidative stress and inflammation [14].

Low serum zinc levels in patients with intractable epilepsy were found in a study by Elshorbagy et al. This study obtained zinc levels of $1.67 \pm 0.33 \mathrm{mg} / \mathrm{L}$ in the epilepsy group and $2.01 \pm 0.48 \mathrm{mg} / \mathrm{L}$ in the control group $(p<0.05)$ [15]. Another study in Egypt also found that the group of children with epilepsy had significantly lower zinc levels compared to control group with mean values of $59.1 \pm 22.7 \mu / \mathrm{dL}$ and $85 \pm 22.2 \mu / \mathrm{dL}$, respectively. 
Electrolytes and some trace elements such as zinc have an important role in the pathogenesis of epilepsy, especially in relation to the increase in free radicals and decreased antioxidants that affect seizure recurrence and resistance to AEDs [16].

Serum zinc levels tend to vary according to daily intake. Hair zinc metabolism and its turnover in the brain are slower than in the peripheral tissues such as the liver, due to the regulatory system of the blood-brain barrier. The half-life for zinc elimination ranges from 16 to 43 days. This suggests that zinc homeostasis in the brain is influenced by chronic zinc deficiency [17], [18]. Research about the correlation between levels of zinc in serum and hair previously showed that there was no correlation between zinc levels in serum and hair $(r=0.066, p=0.631)$. Zinc levels in hair represent a long-term zinc status, whereas zinc levels in serum describe the current condition. Thus, the use of hair to measure zinc levels in the brain is more relevant compared to zinc serum [19]. The cutoff of low hair zinc levels is $\leq 130 \mathrm{mg} / \mathrm{kg}[20]$.

Zinc deficiency affects the occurrence of neurological disorders through NMDA receptors, AMPA, and decrease in GABA activity. Zinc works by binding to the NMDA receptor, thereby inhibiting the activity of NMDA. Zinc shows different affinities to these receptors, depending on the concentration. At relatively low nanomolar concentrations (10-20 nM), zinc binds to the GluN2A subunit of NMDAR, allosterically inhibiting receptor activity. At the higher concentration, it binds to the GluN2B subunit of NMDAR and inhibits NMDAR activity during synaptic phase. At very high concentrations (10-50 $\mu \mathrm{M})$, zinc inhibits NMDAR through voltage-independent allosteric inhibition mechanism.

Zinc may also affect the AMPA receptors at post-synaptic neurons. The AMPA receptors are directly activated by binding to glutamate. These receptors are expressed predominantly on the post-synaptic neuronal membrane and play an important role in the excitatory neurotransmission in brain tissue. High zinc concentrations will result in inhibition of the AMPA receptor that can reduce epileptiform activity.

Zinc is associated with the modulation of glutamic decarboxylase acid activity (an enzyme that plays a role in GABA synthesis) and stimulation of pyridoxal kinase activity, an enzyme that can produce pyridoxal from pyridoxal phosphate, which plays a role in modulating glutamic decarboxylase activity and GABA synthesis. Zinc deficiency will cause increase activity of excitatory neurotransmitters and decrease activity of inhibitory neurotransmitters lead to seizure generation [21].

This study also assessed the relationship between structural abnormalities and DRE. The results showed that structural abnormalities were found more in the DRE group (59.5\%) than in drug-sensitive epilepsy $(35.1 \%)$. Multivariate analysis result showed that structural abnormalities increase the incidence of DRE by 4.1 times. A study conducted by Xue-Ping et al. in 2019 explained that structural brain abnormalities have a significant effect on the incidence of DRE. Changes in the structure and function of the central nervous system can cause hyperexcitation, which is the main mechanism of epilepsy. Brain lesions cause brain cell death and relative glycolysis. One of the mechanisms of DRE is the transporter hypothesis and the structural damage to capillary epithelial cells leads to transporter overexpression and drug resistance [22].

DRE can also be affected by inadequate epilepsy treatment. This recent study showed that children with a duration of therapy $\geq 2$ years were higher in drug resistant group. Children with prolonged epilepsy treatment tend to respond poorly to the initial AEDs. A similar finding was also reported in a systematic review by Xue-Ping et al. which concluded that children with longer treatment tend to become resistant to drugs [22].

The limitations of this study include the study design, consequently, further research with matched case-control or cohort study design is needed. Based on the result of this study that showed the relation of low hair zinc levels with DRE in children, zinc supplementation may be considered in the children with epilepsy, especially in children with risk of DRE.

\section{Conclusion}

Low hair zinc levels have a relation with DRE. Zinc supplementation may be considered in children with high risk of DRE. Further research is needed to examine the effectivity of zinc supplementation to prevent DRE.

\section{Acknowledgment}

We thank all of the patients who participated in this research and all of the research staffs in our hospital.

\section{References}

1. Kwan P, Schachter SC, Brodie MJ. Drug-resistant epilepsy. N Engl J Med. 2011;365:919-26.

2. Kwan P, Arzimanoglou A, Berg AT, Brodie MJ, Hauser WA Mathern $G$, et al. Definition of drug resistant epilepsy: Consensus proposal by the ad hoc task force of the ILAE commission on therapeutic strategies. Epilepsia. 2010;51(6):1069-77. https:// doi.org/10.1111/j.1528-1167.2009.02397.x 


\section{PMıd:19889013}

3. Berg AT, Zelko FA, Levy SR, Testa FM. Age at onset of epilepsy, pharmacoresistance, and cognitive outcomes: A prospective cohort study. Neurology. 2012;79(13):1384-91. https://doi. org/10.1212/wnl.0b013e31826c1b55

PMıd:22972641

4. Widodo D. Risk Factors for Difficultly Cured Epilepsy in Children Under 5 Years Old: Development of a Scoring System to Predict Early, PhD. Indonesia: University of Indonesia; 2012.

5. Suwarba IG. Insidens dan karakteristik klinis epilepsi pada Anak. Sari Pediatri. 2016;13:123-8. https://doi.org/10.14238/ sp13.2.2011.123-8

6. So E. Predictors of outcome in newly diagnosed epilepsy: Clinical, EEG and MRI. Neurol Asia. 2011;16:27-9.

7. Prasad DKV, Shaheen U, Satyanarayana U, Surya Prabha T, Jyothy A, Munshi A. Association of serum trace elements and minerals with genetic generalized epilepsy and idiopathic intractable epilepsy. Neurochem Res. 2014;39(12):2370-6. https://doi.org/10.1007/s11064-014-1439-3

PMıd:25255736

8. Saad K, El-Houfey AA, Abd El-Hamed MA, El-Asheer OM, Al-Atram AA, Tawfeek MS. A randomized, double-blind, placebocontrolled clinical trial of the efficacy of treatment with zinc in children with intractable epilepsy. Funct Neurol. 2015;30(3):1815. https://doi.org/10.11138/fneur/2015.30.3.181 PMıd:26415035

9. Talat MA, Ahmed A, Mohammed L. Serum levels of zinc and copper in epileptic children during long-term therapy with anticonvulsants. Neurosciences. 2015;20(4):341-5. https://doi. org/10.17712/nsj.2015.4.20150336

PMıd:26492112

10. Kipnis PA, Sullivan BJ, Kadam SD. Sex-dependent signaling pathways underlying seizure susceptibility and the role of chloride cotransporters. Cells. 2019;8(5):448. https://doi. org/10.3390/cells 8050448

PMıd:31085988

11. Minardi C, Minacapelli R, Valastro P, Vasile F, Pitino S, Pavone P, et al. Epilepsy in children: From diagnosis to treatment with focus on emergency. J Clin Med. 2019;8(1):39. https://doi. org/10.20944/preprints201810.0114.v1 PMıd:30609770

12. Andrade JP, Paula-Barbosa MM. Protein malnutrition alters the cholinergic and GABAergic systems of the hippocampal formation of the adult rat: An immunocytochemical study. Neurosci Lett. 1996;211(3):211-5. https://doi. org/10.1016/0304-3940(96)12734-8
PMıd:8817578

13. Seven M, Basaran SY, Cengiz M, Unal S, Yuksel A. Deficiency of selenium and zinc as a causative factor for idiopathic intractable epilepsy. Epilepsy Res. 2013;104(1-2):35-9. https:// doi.org/10.1016/j.eplepsyres.2012.09.013 PMıd:23103062

14. Viteva E. Basic cellular and molecular mechanisms of refractory epilepsy: A review of current hypotheses. Mol Cell Epilepsy. 2014;1:e17. https://doi.org/10.14800/mce.17

15. Elshorbagy H, Bassiouny M, Kamal N, Azab A, Ghoneim I. Study of trace elements and role of zinc supplementation in children with Idiopathic Intractable epilepsy. J Pediatr Epilepsy. 2015;5:1567854. https://doi.org/10.1055/s-0035-1567854

16. Eissa MA, Abdulghani KO, Nada MA, Elkhawas HM, Shouman AE, Ahmed NS. Serum zinc and copper levels in a sample of Egyptian epileptic children. Egypt J Neurol Psychiatry Neurosurg. 2020;56:79. https://doi.org/10.1186/s41983-020-00210-2

17. Takeda A, Minami A, Takefuta S, Tochigi M, Oku N. Zinc homeostasis in the brain of adult rats fed zincdeficient diet. J Neurosci Res. 2001;63(5):447-52. https:// doi.org/10.1002/1097-4547(20010301)63:5<447:aidjnr1040>3.0.co;2-c

PMid: 11223920

18. Koç ER, Ilhan A, Null ZA, Acar B, Gürler M, Altuntaş A, et al. A comparison of hair and serum trace elements in patients with Alzheimer disease and healthy participants. Turk J Med Sci. 2015;45(5):1034-9. https://doi.org/10.3906/sag-1407-67 PMid:26738344

19. Han TH, Lee J, Kim YJ. Hair zinc level analysis and correlative micronutrients in children presenting with malnutrition and poor growth. Pediatr Gastroenterol Hepatol Nutr. 2016;19(4):259-68. https://doi.org/10.5223/pghn.2016.19.4.259

PMıd:28090471

20. Zhou T, Li Z, Shi W, Wu L, Christie P. Copper and zinc concentrations in human hair and popular food stuffs in China. Hum Ecol Risk Assess. 2016;23:1229117. https://doi.org/10.10 80/10807039.2016.1229117

21. Tóth K. Zinc in neurotransmission. Ann Rev Nutr. 2011;31:13953. https://doi.org/10.1146/annurev-nutr-072610-145218 PMıd:21548772

22. Xue-Ping W, Hai-Jiao W, Li-Na Z, Xu D, Ling L. Risk factors for drug-resistant epilepsy: A systematic review and meta-analysis. Medicine. 2019;98(30):e16402. https://doi.org/10.1097/ md.0000000000016402

PMıd:31348240 